\title{
Towards Assessment as Learning: Findings from online courses for secondary school teachers Francesca Gratani*
}

\begin{abstract}
Today's school has to deal with several critical issues related to assessment, such as the excessive focus on grades and the lack of a shared understanding of assessment methods and aims. Assessment becomes formative when the evidence gathered is used to adapt teaching practice to pupils' learning needs. Teachers should move towards Assessment as Learning, characterised by appropriate tasks, development of evaluative competence, and the involvement of students in feedback processes. This contribution presents two online research-training courses on assessment in secondary schools. They involved 240 secondary school teachers and consisted of a training and a workshop session. Courses were mainly based on teacher involvement, allowing for recursive feedback processes. We analysed data from an entry questionnaire, a One Minute Paper submitted during the course, and the workshop. The data analysis highlights the main difficulties related to assessment, suggestions, and reflections of the participants. We noticed the importance of workshop and group work to reflect on the transformation of practices. Finally, the interaction with the teachers was indeed valuable in understanding the sustainability of the proposal and refining it.

Key words: assessment as learning; teacher training; secondary school
\end{abstract}

First submission: 06/09/2021, accepted: 08/11/2021

Available online: 21/12/2021

\section{Assessment as learning}

Today's school has to deal with several critical issues related to assessment. Using tests to assess learning achievement often leads to discouragement, frustration and competition in students and causes an excessive focus on grades (Stiggins, 2002; Black and Wiliam, 1998). Most importantly, there is a lack in the sharing assessment methods and their purpose between colleagues, teachers, students, and their families.

\footnotetext{
*Ph.D. candidate, University of Macerata. E-mail: f.gratani@unimc.it.
}

Doi: $10.3280 /$ ess2-2021oa12877 
Assessment becomes formative when the evidence gathered is concretely used to adapt teaching practices to pupils' learning needs. It can promote learning if it offers good information to teachers and students so that both can evaluate themselves, carry out peer evaluation, and modify teaching and learning processes. In this way, we move from an assessment of learning to an assessment for learning (Stiggins, 2002) and, finally, to an assessment as learning (Carless, 2015; Zeng et al., 2018).

The assessment as learning is characterised by three key elements:

- tasks appropriate to the approach;

- development of evaluative competence;

- involvement of students in feedback processes (Carless, 2015, p. 965).

Students monitor their learning and use the feedback to make changes to their skills and knowledge, giving relevance to self and peer evaluation. They have responsibility for their learning and assessment and use strategies for learning and action. Making students' expectations of the task transparent is crucial to give them a picture of 'how they are' so that they can understand (self-assess) 'how they should be'.

According to Jonassen (2003), teachers should assess students as they perform real tasks that they are likely to do in their future. In this sense, teachers can use simulated environments that act as a bridge between the theoretical learning of the classroom and the actual practice of the working environment (Resnick, 1987).

All assessment tools can refer to real-life situations. However, not everything that is real is authentic (Tessaro, 2014). The fundamental distinction, which stems from different theoretical conceptions and led to opposing evaluation approaches, is between traditional school methods of assessment, such as quizzes or oral presentations, and authentic tasks.

Tests retain the stimulus-response approach with a behaviourist imprint (Skinner, 1968; Bryant et al., 2013): the teacher prepares the stimuli (questions or requests), knows the answers or at least the validity criteria, and the pupils are called upon to conform to the expected answers or performances.

The authentic tasks are based on the constructivist approach (Duffy and Jonassen, 2013; Jonassen, 2017) according to which the subject produces knowledge through reflective action in real-life situations. Tasks are complex, open-ended problems that students tackle in order to learn how to use personal knowledge, skills and abilities in a real-life context, and so demonstrate the acquired competence (Glatthorn, 1999; Pellerey, 2004). These complex situations, indeed, stimulate students to find simplex solutions (Berthoz, 2009), by 'mobilising' action patterns and personal resources.

Assessing competence means observing it over time and in its development as a process. Each pathway is open, challenging and authentic, and has a 
formative and evaluation purpose. The rigid succession of training - assessment is eliminated: the assessment process also has a formative value for the student thanks to the sense the pathway has (it has meaning in itself and not as an assessment) and the feedback received. Thus, teachers have to work iteratively on complex processes.

In the Project Based Learning process (Schmidt, Rotgans and Yew, 2011; Hung, 2019; Kolmos et al., 2008), the activity is evaluated to verify if:

- students correctly apply prior knowledge in solving the problem;

- students can apply "high-level conceptual and analytical skills" (Fishman and Dede, 2016, p. 1274) i.e. manage processes, make choices and justify their choices;

- they are aware of the processes activated.

Simple tools cannot be used for such a complex evaluation process. To assess these aspects we need supporting tools, such as: systematic observations; cognitive autobiographies; logbooks; rubrics; learner dossiers; portfolios and ePortfolios. Rubrics are one of the most valuable tools since they allow us to embed assessment and training in line with the approach to competence assessment described above. They help the teacher to maintain objectivity and guide students by indicating what is important in the process and in the task and by communicating performance levels. In turn, students know the expectations and understand strengths and weaknesses more easily.

\section{The research-training project}

This article presents two research-training courses on assessment methods that took place in an online mode between July and October 2021. The courses were organised by the School Office of the Marche Region (Italy) and held by the University of Macerata. They lasted 30 hours and involved 150 lower secondary school teachers (LSS) and 90 upper secondary school (USS) teachers. An entry questionnaire revealed that in both courses participants mainly teach subjects related to the humanistic-literary field $(69.8 \%$ LSS; $36.5 \%$ USS), followed by the linguistic-artistic field (17.1\% LSS; $21 \%$ USS), and the scientific-technological field (9.6\% LSS; $23.5 \%$ USS).

The courses schedule, summarised in Tab. 1, consisted of two main parts: the training session (10 hours) and the workshop session (20 hours). The following sub-sections present a description of the training session (see 2.1), the workshop session (see 2.2), and the methodology (see 2.3). 


\begin{tabular}{|c|c|c|c|}
\hline Part & Mode & Duration & Activities \\
\hline \multirow[t]{2}{*}{ Training } & Plenary & $2.5 \mathrm{~h}$ & Assessing subjects and certifying competences \\
\hline & & $\begin{array}{l}2.5 \mathrm{~h} \\
2.5 \mathrm{~h}\end{array}$ & $\begin{array}{l}\text { From task to process - the construction of rubrics } \\
\text { Summative assessment and the ePortfolio }\end{array}$ \\
\hline \multirow[t]{4}{*}{ Workshop } & $\begin{array}{l}\text { Groups and } \\
\text { sub-groups }\end{array}$ & $3 \mathrm{~h}$ & $\begin{array}{l}\text { From authentic tasks to processes and competences } \\
\text { (task 1) }\end{array}$ \\
\hline & & $3 \mathrm{~h}$ & The construction of rubrics (task 2) \\
\hline & & $12 \mathrm{~h}$ & Project work (asynchronous) \\
\hline & & $2 \mathrm{~h}$ & Presentation of project works \\
\hline Training & Plenary & $2.5 \mathrm{~h}$ & Reflection on project work and final synthesis \\
\hline
\end{tabular}

\subsection{Training session}

The training session consisted of four plenary meetings for each course on the Zoom platform. Every meeting presented the same structure: introduction; topics presentation; discussion; debriefing and relaunch. The meetings were focused on the following topics: assessing subjects and certifying competences (1); from authentic task to process - the construction of rubrics (2); summative assessment and the ePortfolio (3); reflection on project work and final synthesis (4). The first three meetings had a preparatory function for the workshop. The last meeting, instead, was held after the workshop as a final moment of debriefing and collective reflection. After each meeting, we made the material presented and discussed (slides and audio-video recordings) available in a shared repository to allow teachers to return to it in a reflective way.

Meeting 1: it started from the analysis of teachers' expectations expressed in the entry questionnaire. Then, it continued with the presentation of the assessment as learning and the authentic task. Specifically, we defined a task as authentic if it is linked to real problems and perceived by students as related to their context, close to their experiences; challenging if it presents a motivating problematic situation that cannot be solved by performing standard procedures but requires divergent solutions; and open if it offers several solutions, allowing the teacher to devolve the learning objective (Brousseau, 1986) and the student to take responsibility and make choices (Rossi et al., in press). We also illustrated the tripartition scheme of an authentic task. It consists of three main moments: the challenging and generative situation, the structured delivery, and the scaffolding. The situation should be as authentic as possible and close to the student's experience. It can happen naturally or induced / highlighted by the teacher. Then, the task should be detailed enough to guide the student, but free enough to avoid suggesting solutions and leave all 
possible avenues open. Finally, the teacher should provide a scaffolding strategy, such as materials and mediators to support the teaching-learning process, a metacognitive form and/or a rubric for self-assessment and reflection. The meeting closed with a reflection on what it means to work on competences. We suggested to observe them in their becoming, rather than measuring them, and to use descriptors instead of numbers.

Meeting 2: it started with an analysis of the authentic tasks proposed by the teachers to highlight the underlying processes. We then presented possible links between the processes identified and the 2018 European competences (Raccomandazione del Consiglio, 2018). We also pointed out that some processes are repeated; we can therefore identify families of processes or dimensions. Finally, we proposed constructing rubrics aimed at analysing these processes. Specifically, we distinguished between analytical and synthetic rubrics, reporting some examples. The first one is more task-related and is developed from the families of processes (dimensions) that characterise the task. These dimensions are broken down into micro-indicators and related levels/descriptors. The synthetic rubric, instead, focuses on the few dimensions of the process on which the teacher wants to work most during the year and that recur most in the various tasks. It is therefore divided into more generic macroindicators and descriptors and useful to support interdisciplinary and longitudinal assessment.

Meeting 3: it aimed at clarifying how to assess disciplinary and practical knowledge in the disciplines and how to come at a summative assessment. We proposed to start from the processes (micro perspective), where disciplinary and practical knowledge intertwine and support each other, to move to a macro perspective, where it is possible to analyse and describe competences and disciplines separately. Finally, we introduced the Balanced assessment perspective, according to which using different assessment instruments facilitates appreciation of many aspects of student learning and the emergence of different knowledge, skills, and attitudes (Burke, 2010). We thus presented, as a further example of a relevant tool, the ePortfolio.

Meeting 4: it started by analysing some project works carried out during the workshop and the difficulties encountered. Then, we took up and specified in more detail how to arrive at the end-of-year summative assessment. Finally, we closed the meeting by exploring the teachers' views on the sustainability of the proposal.

\subsection{Workshop session}

The workshop session consists of three synchronous group meetings (8 hours) and 12 hours of asynchronous project work. We first divided the teachers 
into macro-groups of 20 participants, according to their subject area, and assigned a tutor for each group. In turn, the participants were then able to work in micro-groups of 4-5 people to carry out the project work. The meetings were held on the University's Microsoft Teams platform where we generated the rooms for teamwork. The workshop activities follow the path outlined during the training part: transition from authentic tasks to processes and competences (1); construction of the rubrics (2); presentation of project works and final debriefing (3). The first two meetings included an introductory phase, a modelling phase with task assignment, a phase of work in micro-groups, and a debriefing phase. The project work was the results of the two assigned tasks, related to the key steps of the training:

- Task 1: Design of an authentic, open and challenging task according to the tripartition scheme. Identification of underlying processes and related competences.

- Task 2: Identification of the families of processes (dimensions of the rubrics). Construction of synthetic and analytical rubrics.

The groups would then complete the tasks asynchronously and submit them in for feedback at the next meeting. During the workshop, the teachers were able to play an active role and initiate a process of reflection and revision of their evaluation practices enriched by the comparison with others during the teamwork and the macro-group feedback. After the final debriefing, we asked the teachers to finalise their project works with any revisions needed and make a final delivery. On this occasion, we also asked for consent to publish them in a public repository.

\subsection{Methodology}

The structure of the training courses is mainly based on the dialogue with teachers and their personal involvement. In fact, before the start of the courses, we asked the participants to fill in an entry questionnaire to get a picture of the target group, their expectations and their current assessment methods. It consisted of open and closed questions and was designed to collect:

- professional information (subject/s, school, etc.);

- motivations and expectations related to the course (open questions);

- the most used methods to assess learning (open question);

- the most critical and relevant elements related to assessment (closed and open question);

- the attitude towards the integration of learning assessment and certification of competences (closed question).

The data collected was useful for structuring the training course and calibrating the proposal. Then, during the meetings, we placed particular 
emphasis on interaction with the teachers, reserving, as mentioned above, specific spaces for discussion and debate.

This continuous interaction differentiated such courses from purely theoretical and transmissive ones and enabled recursive feedback processes (Carless, 2019) between trainers and participants.

In this regard, at the end of the second meeting, we administered a "OneMinute Paper" (OMP) (Angelo and Cross, 1993) useful to promote selfregulation processes and dialogic feedback (Nicol and MacFarlane-Dick, 2006). It asked for feedback from teachers in the following areas:

1. Keywords considered most significant (central, useful, unexpected);

2. Concepts that stuck in the mind and why;

3. Concepts or terms that seem unclear and need further investigation.

Finally, as mentioned above, for the workshop session we set up work in groups to increase feedback processes, focusing on their productions. This workshop model allowed us to collect data on main difficulties, reflections, and suggestions.

\section{Results}

In this contribution we will report the data from the entry questionnaire and the OPM (see 3.1 and 3.2), and some first data from the workshop (see 3.3).

\subsection{The entry questionnaire}

The entry questionnaire was administered through a Google form and was not mandatory. We therefore collected responses from 105 LSS and 32 USS.

As regards the motivations to approach the courses, they are mainly linked to organisational issues (role as Special Projects Teacher) and professional growth (responding to current evaluation needs, deepening the relationship between the assessment of learning and competences).

Among the most used tests to assess learning, almost all teachers mention oral and written tests (structured and/or semi-structured), while only a minority refers to practical tests $(7.3 \% \mathrm{LSS} ; 3.2 \%$ USS) and authentic or reality tasks (13.6\% LSS; $22.5 \%$ USS).

Then, teachers recognized as the most relevant critical elements of the assessment: avoiding students focusing too much on grades (43.3\% LSS; $50 \%$ USS); activating formative assessment paths (20.2\% LSS; $17.5 \%$ USS); constructing valid tests (19.2\% LSS; $12.5 \%$ USS), maintaining the objectivity of assessment (11.5\% LSS; $12.5 \%$ USS) and communicating/sharing criteria 
and outcomes with students (5.8\% LSS; 7.5\% USS). From the analysis of these responses, we have therefore identified three main categories of critical aspects:

- the formative value of assessment: making students aware of it, triggering processes of self-assessment and reflection on their mistakes and thus improvement;

- the objectivity: reducing or eliminating subjective interpretations, assessing the student's skills and progressive growth, choosing tests appropriately and taking several elements into account;

- the sharing: discussing criteria and methods with families and especially with colleagues.

Finally, concerning the integration between the assessment of learning and the certification of competences, we found that $56.7 \%$ LSS and $53.8 \%$ USS assess disciplinary knowledge and competences together, 29.8\% LSS and $20.5 \%$ USS assess them separately, while $9.6 \%$ LSS and $10.3 \%$ USS assess mainly the disciplinary knowledge.

\subsection{The OMP}

The OMP was administered through a Google form during the end of the second training meeting and was not mandatory. We therefore collected responses from 144 LSS and 59 USS.

Question 1: analysing the answers to this question we found an alignment (Laurillard, 2012) between the main themes of the training programme and the keywords chosen by the participants. Indeed, the most frequently mentioned words were: process, rubric, competences, task, self-assessment (LSS) and rubric, process, shared, task, competence, evaluation, self-assessment (USS). We can also easily notice a strong correspondence between the words identified by the teachers of the two school orders.

Question 3: this question was particularly relevant for the feedback process. In fact, identifying the possible misconceptions and the unclear concepts allowed us to understand the most critical aspects of the training proposal and to improve it. Specifically, we summarised the emerged concepts in the following categories:

- designing and using rubrics: how to unambiguously decline the descriptors avoiding unclear adjectives and highlighting observable behaviours; how to design synthetic rubrics and analytical rubrics;

- designing authentic tasks, particularly concerning scientific subjects with unambiguous results.

- linking authentic tasks, processes, and competences: how to combine disciplinary with intra- and interpersonal learning (Fishman and Dede, 
2016); how the process assessment can flow into a final assessment and be shared with the students and parents transparently;

- assessing the individual student during group work;

- planning the assessment process: how many authentic tasks to propose, how many rubrics to construct, how to facilitate the sharing of rubrics between teachers, how to involve the school at a collegial level on a different approach to assessment.

\subsection{The workshop}

At the end of the workshop, we collected the main difficulties that emerged in the application phase and any reflections or suggestions to be discussed during the last webinar.

Concerning the difficulties, a critical point that emerged in almost all the workshops was the identification of processes. Teachers are in fact not very used to making explicit the processes underlying the task and reflecting on them. They often listed activities rather than processes or mainly mentioned disciplinary processes, considering less those linked to motivation and selfassessment. As regards rubrics, there are conflicting opinions among the various groups regarding sustainability and ease of construction of the analytical or synthetic rubric (which is easier to construct). We believe that this also depends on the previous habits of the teachers and their possible misconceptions regarding the rubrics, such as associating disciplinary knowledge with analytical rubric and practical knowledge with synthetic rubric or considering one type of rubric more relevant than the other. Some participants also point out terminology as a problematic element. Indeed, the use of different terminology in training courses run by different university researchers can lead to misunderstandings and confusion. Finally, a few teachers raise doubts about the last step from the levels of the rubrics to the final grade. In particular, levels are often expressed through verbal judgement whereas in secondary school a numerical grade in tenths is required.

Among the personal considerations that emerged from direct reflection on the work carried out, one teacher emphasises the fruitfulness of group work in developing the rubrics and therefore expresses doubts about the sustainability of developing them alone. Another one, instead, questions the sustainability of their proposed authentic task (requiring about 10-12 hours of work in class), reflecting on how much can be considered daily and routine. We consider these self-reflections very important, especially in the perspective of self-regulation and improvement.

Then, interesting suggestions and developments also emerged during the debate. Specifically, some teachers asked if it was possible to identify and share 
macro-families of constant processes and to standardise descriptors in the same school and between schools to avoid assessing students with different rubrics. Moreover, they also ask how to best disseminate and share the training received. To this end, some of them expressed the willingness to share their works in a repository to increase the possibilities for exchange and mutual enrichment.

\section{Conclusions}

The analysis of the data made it possible to highlight the main difficulties and critical issues related to assessment and thus the need for training on Assessment as Learning. Moreover, we found interaction with participants extremely valuable in understanding the sustainability of the proposal and refining it. Specifically, we noticed the importance of workshop and microgroups work to reflect on the transformation of their practices (Rossi et al., in press). For this reason, we have decided to structure the next training course mainly on working directly on the contextualised practices brought by the teachers. A future analysis of the workshop session will include the analysis of the dimensions chosen for the construction of the rubrics to identify the most recurrent ones. We will also investigate how disciplinary and practical knowledge were analysed and whether they were given the same priority. Future perspectives also include the organisation of a focus group with teachers who are testing the proposal in their practice. We would like to point out issues such as possible insights, the most innovative aspects or those that have most influenced their practice. These considerations will be the basis for planning and implementing the next training course.

\section{References}

Angelo T.A., Cross K.P. (1993). Classroom Assessment Techniques (2nd ed). San Francisco: JosseyBass.

Berthoz A. (2009). La Simplexité. Paris: Odile Jacob.

Black P., Wiliam D. (1998). Assessment and Classroom Learning. Assessment in Education: Principles, Policy \& Practice, 5(1): 7-74. DOI: $10.1080 / 0969595980050102$.

Brousseau G. (1986). Fondement et Méthodes de la Didactique des Mathématiques. Recherches en didactique des mathématiques, 7(2): 33-115.

Bryant L.C., Vincent R., Shaqlaih A. and Moss G. (2013). Behaviorism and behavioral learning theory. In: Irby B.J., Brown G., Lara-Alecio R. and Jackson S., eds., The handbook of educational theories (pp. 91-103). IAP Information Age Publishing. 
Burke K. (2010). Balanced assessment: From formative to summative. Solution Tree Press.

Carless D. (2015). Exploring learning-oriented assessment processes. Higher Education, 69(6): 963-976.

Carless D. (2019). Feedback loops and the longer-term: towards feedback spirals. Assessment \& Evaluation in Higher Education, 44(5): 705-714. DOI: 10.1080/02602938.2018.1531108.

Duffy T.M., Jonassen D.H. (2013). Constructivism and the technology of instruction: A conversation. Routledge.

Fishman B., Dede C. (2016). Teaching and technology: New tools for new times. In: Gitomer D.H. and Bell C.A., eds., Handbook of Research on Teaching. Washington, DC: American Educational Research Association.

Glatthorn A.A. (1999). Performance standards and authentic learning. Larchmont, NY: Eye of education.

Hung W. (2019). Problem design in PBL. In: Moallem M., Hung W. and Dabbagh N. eds., The Wiley handbook of Problem-based learning (pp. 249-272). Hoboken, NJ: Wiley-Blackwell.

Jonassen D.H. (2003). Learning to Solve Problems: An Instructional Design Guide. San Francisco, CA: Pfeiffer.

Jonassen D.H. (Ed.). (2017). Learning to solve complex scientific problems. Routledge.

Kolmos A., Du X. Holgaard J.E. and Jensen L.P. (2008). Facilitation in a PBL environment. UCPBL UNESCO Chair in Problem Based Learning.

Laurillard D. (2012). Teaching as a design science. Building Pedagogical Patterns for Learning and Technology. London: Routledge.

Nicol D., McFarlane-Dick D. (2006). Formative assessment and self-regulated learning: A model and seven principles of good feedback practice. Studies in Higher Education, 31(2): 199-218. DOI: 10.1080/03075070600572090.

Pellerey M. (2004). Le competenze individuali e il portfolio. Roma: La Nuova Italia.

Raccomandazione del Consiglio (2018). Competenze chiave per l'apprendimento permanente. Quadro di riferimento europeo. Text available at: https://eurlex.europa.eu/legal-content/IT/TXT/PDF/?uri=CELEX:32018H0604(01). Last accessed 2021/10/19.

Resnick L.B. (1987). The 1987 Presidential Address: Learning in School and out. Educational Researcher, 16(9): 13-20. DOI: 10.3102/0013189X016009013.

Rossi P.G., Giannandrea L., Gratani F., Laici C., Tarantino A. and Paviotti G. (in press). Assessment as learning: transforming practices with secondary school teachers. ICERI2021 Proceedings. Valencia: IATED.

Schmidt H.G., Rotgans J.I. and Yew E. (2011). The process of problem-based learning: What works and why. Medical Education, 45(8): 792-806. DOI: 10.1111/j.13652923.2011.04035.x.

Schmidt H.G. (1993). Foundations of problem-based learning: some explanatory notes. Medical Education, 27: 422-432. DOI: 10.1111/j.1365-2923.1993.tb00296.x.

Skinner B.F. (1968). The technology of teaching. New York, NY: Appleton-CenturyCrofts. 
Stiggins R.J. (2002). Assessment crisis: the absence of assessment FOR learning. Phi Delta Kappa, 83(10): 758-765. DOI: 10.1177/003172170208301010.

Tessaro F. (2014) Compiti autentici o prove di realtà? FORMAZIONE \& INSEGNAMENTO. Rivista internazionale di Scienze dell'educazione e della formazione, 12(3): 77-88. DOI: 107346/-fei-XII-03-14_07.

Zeng W., Huang F., Yu L. and Chen S. (2018). Towards a learning-oriented assessment to improve students' learning - a critical review of literature. Educational Assessment, Evaluation and Accountability, 30: 211-250. DOI: 10.1007/s11092018-9281-9. 